\title{
Temporal and Spatial Effect of Surrounding Rock and Supporting Construction of a Large Soil Tunnel
}

\author{
Wanjun Ye $\left(\mathbb{D},{ }^{1}\right.$ Yuntao Wu $\left(\mathbb{D},{ }^{1}\right.$ Ming Chen $\mathbb{D}^{2},{ }^{2}$ and Chong Gao ${ }^{3}{ }^{3}$ \\ ${ }^{1}$ School of Civil Engineering \& Architecture, Xi'an University of Science and Technology, Xi'an, Shaanxi 710054, China \\ ${ }^{2}$ The 4th Engineering Co., Ltd of China Railway 12th Bureau Group, Xi'an 710021, China \\ ${ }^{3}$ China Railway 19th Bureau Group Rail Transit Engineering Co., Ltd, Beijing 10300, China
}

Correspondence should be addressed to Yuntao Wu; 19104053010@stu.xust.edu.cn

Received 10 March 2021; Revised 12 April 2021; Accepted 24 April 2021; Published 7 May 2021

Academic Editor: Walid Oueslati

Copyright ( $\odot 2021$ Wanjun Ye et al. This is an open access article distributed under the Creative Commons Attribution License, which permits unrestricted use, distribution, and reproduction in any medium, provided the original work is properly cited.

Based on the Zaosheng No. 3 tunnel of the Yinchuan-Xi'an high-speed railway, the surrounding rock pressure, contact pressure of the primary support, and secondary lining and internal force of the secondary lining concrete are systematically tested using a vibrating wire sensor, and the correlation between the advance construction distance and the surrounding rock release rate is studied with finite element software. The results show that the pressure on the surrounding rock is low when the deeply buried soil tunnel is excavated and can be divided into three stages: rapid growth, slow growth, and flattening with time. It is more reasonable to calculate the surrounding rock pressure by using tunnel planning calculations. For the contact pressure, although the value of each measuring point in the inverted arch changes a little, the arch pressure obviously has the characteristics of rapid growth and a sharp rebound. Most of the test points of the second lining concrete show a compression state, which is far less than the ultimate compressive strength. At the same time, the initial support of the tunnel bears a large load, while the secondary lining bears a relatively small force, and the load sharing ratio of the two ranges between 0.1 and 0.7 ; with the progress of the excavation section, the surrounding rock deformation (deformation release rate) increases gradually. When the excavation face is close to the monitoring section, the deformation (deformation release rate) is the most severe. With the increase in the distance between the excavation section and the monitoring section, the deformation (deformation release rate) tends to be flat.

\section{Introduction}

The space-time effect of tunnel refers to the active mobilization of two types of self-bearing constraints on the surrounding rock, namely, the "semicircular dome" constraint in the axial direction and the "circular" constraint in the cross-sectional direction during tunnel excavation [1]. These constraints are supported by dynamic adjustments to achieve a steady state in the tunnel. The step method is often used by designers of large-section railway tunnels because of its flexibility, applicability, and high stability of the excavation surface, while utilizing the tunnel space-time effect. This method is suitable for the design of large-section railway tunnels, especially to address the low mechanical strength of surrounding rocks, the high water sensitivity, and the development of vertical joints [2-5]. However, a large section is divided into many small sections to distribute excavation and support. This condition creates numerous excavation steps and complicates the construction process. The surrounding rock is greatly influenced by the excavation steps. Therefore, studying the spatial effects of the construction states of large soil tunnels sections is of great importance.

In recent years, tunnel construction technology and the mechanical behavior of tunnel support structures under special engineering geological conditions have been widely investigated [6-10]. These problems remain challenging with the continuous progress of engineering projects, especially the continuous construction of high-speed railway networks. During the tunnel construction process, the vault or back arch structure is a focus of attention as a sensitive location of tunnel damage. The long-term monitoring of vault 
settlement and back arch forces through field testing can enable the timely analysis of test tunnel stability and the optimization of traditional design methods [11-14]. The type of geotechnical body directly determines the stress distribution in a tunnel perimeter, especially for specific formations, such as upper soft-bottom hard, mixed pebble strata, and soft perimeters [15-19]. This body often exhibits different failure modes due to the differences in perimeter properties. The support structure, as a vital part of tunnel engineering, is an important link in preventing tunnel instability. Extensive research has shown that the type of bonding surface significantly influences the primary and secondary linings [20]. Specifically, the thickness of the waterproof membrane and the roughness of the substrate between them have a significant influence on the mechanical characteristics of the lining [21]. Tunnel lining mechanics under asymmetric loading exhibit large differences with declination angle [22]; this condition is the main reason for the differences in longitudinal cracking in tunnels [23]. The above studies have shown that tunnel stability is mainly due to the combined effect of the mechanical properties of the surrounding rock and the performance of the supporting structure, which affect and constrain each other. In addition to the design of the tunnel itself, the type of surrounding rock, the characteristics of the lining, and the type of load, the constructional state is the leading cause of the stress distribution in the surrounding rock and the mechanical characteristics of the supporting structure based on the experience in long-term engineering practice. However, the constructional state has been seldom discussed in related studies.

This study considers the Zaosheng No. 3 tunnel of the Yinchuan-Xi'an high-speed railway. The tunnel's engineering geological conditions, support parameters, and specific construction procedures are investigated. Field measurements are conducted on the surrounding rock pressure, lining pressure, and concrete internal force for long-term tests. This process is performed to explore the internal force variation law and transmission mechanism of composite linings during the construction process. A numerical calculation model is established to describe the temporal and spatial effects of tunnel excavation by introducing the load release to guide the relevant engineering practice.

\section{Project Overview}

2.1. Engineering Background. The Yinchuan-Xi'an highspeed railway passes through the old revolutionary areas of Shaanxi, Gansu, and Ningxia, where the strata have been aggressively active since the Mesozoic and the land has been repeatedly uplifted. After the Cenozoic, wind-carried yellow sand was gradually deposited over the original landform, forming a broad loess plain. In the late Quaternary, the land was uplifted to form the Loess Plateau, and the loess tableland area with Dongzhi and Zaosheng tablelands as the core gradually formed through water erosion. The thickness of the loess overburden is large, and the information of the soil layer is complete, thereby providing certain geological conditions for exceptional stratum exposure. With the construction of the high-speed railway, unique strata, such as earth-rock boundaries, soft plastic loess, and weak expansive paleosols, appear along the line. These conditions have presented difficulties restricting tunnel construction (Figure 1 for details).

The test sections include DK-190+617 and DK-190 + 645 of the Zaosheng No.3 tunnel. In accordance with the relevant data, this tunnel was selected because it is centrally located in the loess plateau, and the water table in this area is relatively high. This condition prevents the rich groundwater environment from affecting tunnel construction and operation. The thick layer of paleosol soil was chosen as the tunnel excavation stratum due to the dense structure of the paleosol with strong water-insulating properties. In accordance with the survey data, the coating is located in the lower part of the loess soil with a dip angle of approximately $180-200 \mathrm{~m}$ from the loess surface, and the layer thickness is relatively thick.

2.2. Tunnel Design Parameters. As a passenger dedicated line, the design speed of the Yinchuan-Xi'an high-speed railway is $250 \mathrm{~km} / \mathrm{h}$ with a reserved speed of $350 \mathrm{~km} / \mathrm{h}$. During the design, the tunnel section was designed as a three-centered circular section with a distance from the top to the bottom of the arch of $12.68 \mathrm{~m}$ and a maximum length of $14.90 \mathrm{~m}$ from the waist of the hooks on two sides, with a design section area of $153.82 \mathrm{~m}^{2}$. This design follows the international standards and considers the possible influence of hydrostatic pressure and bottom drum. The tunnel association criteria for section classification indicate that the tunnel is an extra-large section tunnel.

The tunnel design was fully guided by the new Austrian Tunneling Method. The composite lining was selected for the tunnel support due to the weak swelling characteristics of the surrounding rock. Bolt shotcrete support was used for the initial support. A flexible structure was formed after the initial support. This structure allows the surrounding rock to have a certain deformation but limits large deformations. The secondary lining and integral concrete, as a rigid structure, can well limit the development of deformation when the deformation of the initial support is small. During the site construction, the steel arch frame and steel mesh were initially installed, and the circumferential anchor rod and foot lock were applied when the surrounding rock was excavated. A protective layer of shotcrete shall was sprayed. The secondary lining was formed by binding the circumferential reinforcement, laying geotextile, applying, applying waterproof board, and pouring concrete. The specific support parameters are shown in Table 1.

2.3. Tunnel Excavation Parameters. The tunnel was excavated with the "three benches and seven steps to reserve core soil" method. This method divides the palm surface into seven excavation surfaces, and the steps are staggered and advanced in parallel along the tunnel longitudinally. This method has a small exposed area for a single excavation and a relatively stable working surface. The process can be 


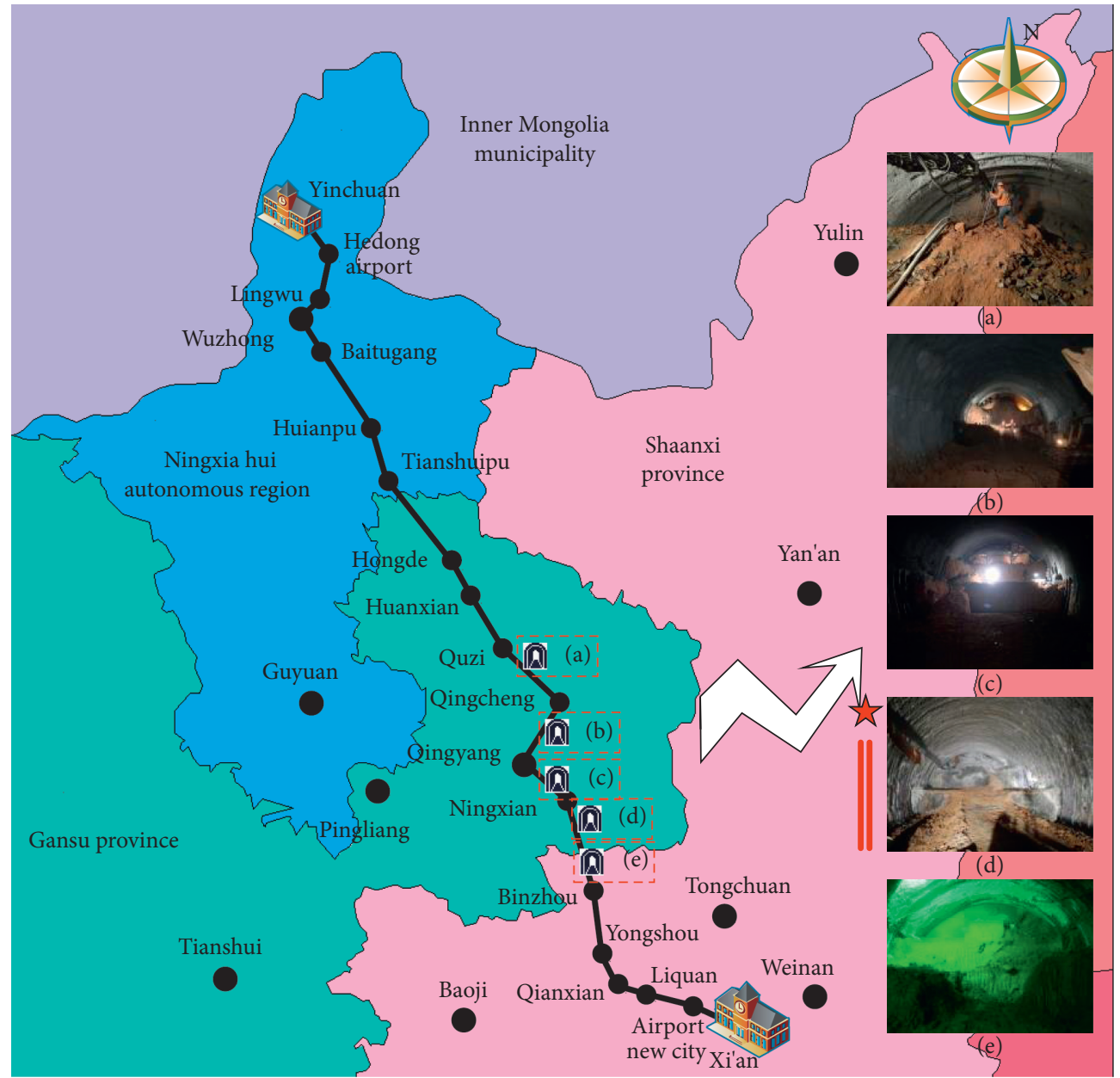

Figure 1: Yinchuan-Xi'an high-speed rail route map. (a) Earth-rock tunnel. (b) Red clay tunnel. (c) Soft plastic loess tunnel. (d) Weak expansive paleosol tunnel. (e) Collapsible loess tunnel.

TABLE 1: Initial support design parameters.

\begin{tabular}{|c|c|c|c|}
\hline \multirow{2}{*}{ Name } & \multirow{2}{*}{ Position } & \multicolumn{2}{|c|}{ Parameter } \\
\hline & & Diameter/mm & Length/m \\
\hline Hot rolled seamless steel pipe & $140^{\circ}$ range of arch & 42 & \\
\hline Mortar bolt & Sidewall & 22 & 4.0 \\
\hline Locking catheter & Arch foot & 42 & \\
\hline \multirow[t]{2}{*}{ Connecting bar } & Between adjacent arches & \multicolumn{2}{|c|}{$\phi 22$} \\
\hline & Initial spraying & \multicolumn{2}{|c|}{$5 \mathrm{~cm}$} \\
\hline \multirow{3}{*}{ Concrete } & Second lining arch & \multicolumn{2}{|c|}{$50 \mathrm{~cm}$} \\
\hline & Secondary lining low side wall & \multicolumn{2}{|c|}{$60 \mathrm{~cm}$} \\
\hline & Double lining invert & \multicolumn{2}{|c|}{$27 \mathrm{~cm}$ thickness } \\
\hline Steel arch & Holocycle & \multicolumn{2}{|c|}{ Type I20 } \\
\hline
\end{tabular}

adjusted in time when the geological conditions change. The core soil is reserved, thereby preventing the unexcavated surrounding rock from extruding out along the adjacent surface. This method is favorable for construction machinery. However, during the excavation process, the step height must be strictly controlled within a range of $2-3 \mathrm{~m}$, and the step width must be kept at 3-5 $\mathrm{m}$. The distance from the back arch to the excavation surface is less than $35 \mathrm{~m}$, and the secondary lining is less than $90 \mathrm{~m}$ from the palm surface of the safety step. The specific construction indicators are as follows (Figure 2).

The secondary lining is usually an essential long-term load-bearing structure. Its stability is closely related to the characteristics of the surrounding rock engineering, excavation method, construction process, and other factors. Therefore, the choice of a suitable method and time plays a decisive role in improving the stability of the tunnel. The secondary lining of the tunnel is mainly divided into nine 


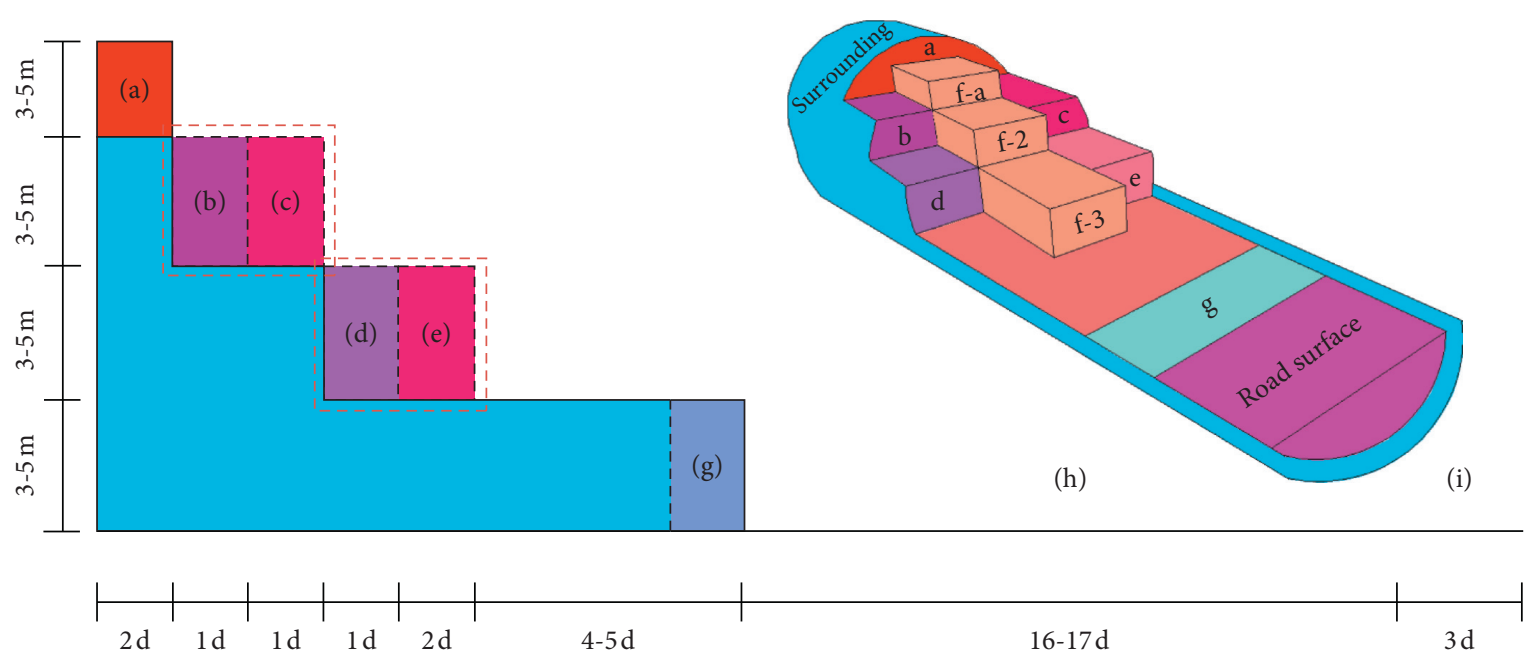

Figure 2: Three-step and seven-step excavation. (a) Excavation of upper stage, (b) left of middle step, (c) right of middle step, (d) left of lower step, (e) right of lower step, (f) excavation of core soil, (g) excavation of inverted arch, (h) clamping secondary lining formwork, and (i) removal of secondary lining formwork.

steps: tying of reinforcement $\longrightarrow$ clamping of secondary lining back arch $\longrightarrow$ pouring of secondary lining back arch $\longrightarrow$ pouring of road surface $\longrightarrow$ tying of ring reinforcement $\longrightarrow$ ring clamping $\longrightarrow$ pumping of concrete $\longrightarrow$ ring dismantling of mold $\longrightarrow$ maintenance (Figure 3). In the construction process of each progress, reinforcement binding and mass concrete pouring are extremely important.

2.4. Arrangement of Test Elements and Measuring Points. In accordance with the research needs, vibrating wire sensors were used to monitor the surrounding rock pressure, the contact pressure of the primary and secondary liners, and the internal force of the secondary concrete lining. During the monitoring, 3, 2, 2, and 3 groups of monitoring instruments were installed in the upper, middle, and lower steps and the back arch. The locations of the monitoring points are shown in Figure 4.

When monitoring the contact pressure between the primary support and the secondary lining, the waste waterproof board is cut into a $15 \mathrm{~cm} \times 15 \mathrm{~cm}$ square, and the earth pressure box is wrapped and adhered to the laid waterproof board. This box is used on a hot melting machine to fix the cut waterproof board on the laid waterproof board. A homemade fixing device is used to make one end of the pressure box close to the pressure box when the pressure box is installed at the inverted position. The other end is welded with the secondary lining reinforcement to provide reaction support. For the installation of a concrete strain gauge, the two ends of the sensor are bound with iron wire and placed in the middle of the steel bars on the inside and outside. The line is placed in the hose and wrapped with geotextile to prevent the cable from being damaged during casting. The clamped formwork is removed from the small sidewall.

\section{Field Test}

The tunnel is greatly affected by the cross-section form, excavation method, and other factors. The "three benches and seven steps" excavation method divides the tunnel section into seven small sections and excavates them in different procedures. Therefore, the construction steps are divided into nine phases: excavation of upper stage $\longrightarrow$ left of middle step $\longrightarrow$ right of middle step $\longrightarrow$ left of lower step $\longrightarrow$ right of lower step $\longrightarrow$ excavation of inverted arch $\longrightarrow$ construction of secondary lining inverted arch $\longrightarrow$ construction of circumferential second lining $\longrightarrow$ monitoring end. These steps are used to explore the influence law of each process on the tunnel surrounding rock pressure. The nine steps are marked, as shown in Figures 5 and 6.

Each construction step is simplified to the form of English letters and subscripts due to the complexity of tunnel construction technology and numerous procedures. This process is performed to clarify the time history curve. Specifically, excavation of upper bench $\longrightarrow S_{1}$, excavation of left middle bench $\longrightarrow S_{2}$, excavation of right middle bench $\longrightarrow S_{3}$, excavation of left lower step $\longrightarrow S_{4}$, excavation of right lower step $\longrightarrow S_{5}$, excavation of inverted arch $\longrightarrow S_{6}$, construction of secondary lining inverted arch $\longrightarrow S_{7}$, construction of secondary lining inverted arch, make circumferential secondary lining $\longrightarrow S_{8}$, and end of monitoring $\longrightarrow S_{9}$. The construction steps in the time history curve of surrounding rock pressure, contact pressure, and secondary lining concrete are marked in accordance with the above codes.

3.1. Surrounding Rock Pressure. The test is mainly conducted in the Zaosheng No.3 tunnel of the Yinchuan-Xi'an highspeed railway. The test is not representative because the shotcrete was not sprayed when the sensor was installed. The surrounding rock pressure should be measured when the shotcrete is completed. However, the process takes a long time, and the environment is poor. Thus, entering the excavation face makes it impossible to read the data. Therefore, the data are all read in the day after the completion of initial concrete spraying, and the time axis starts from day one: 


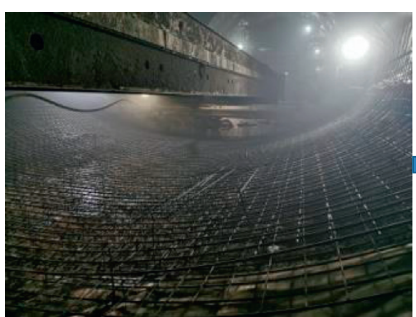

(a)

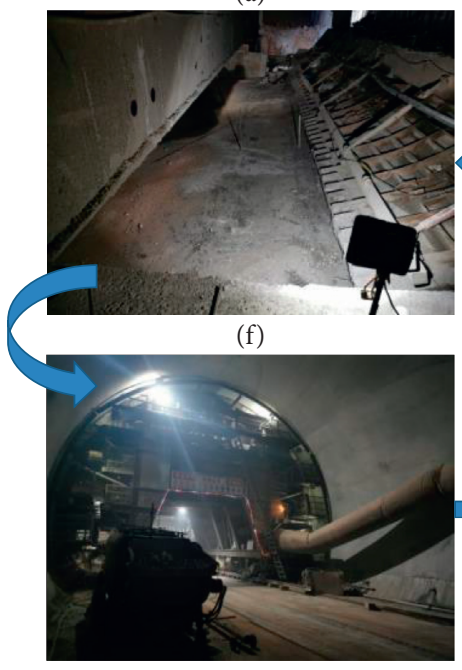

(g)

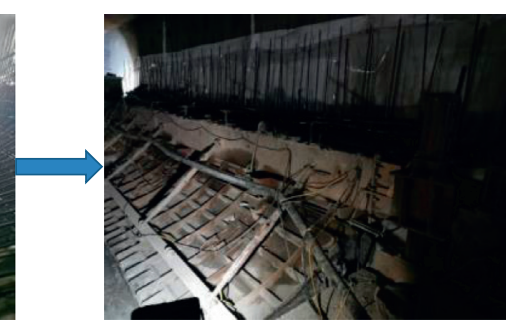

(b)

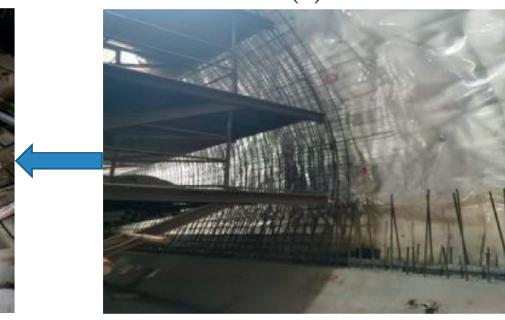

(e)

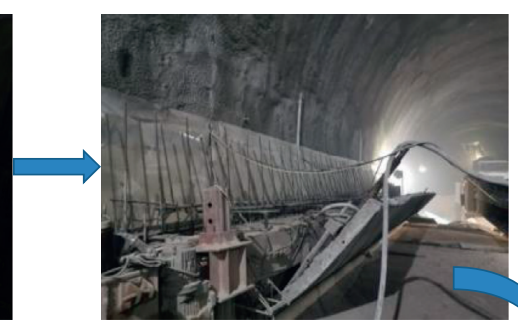

(c)

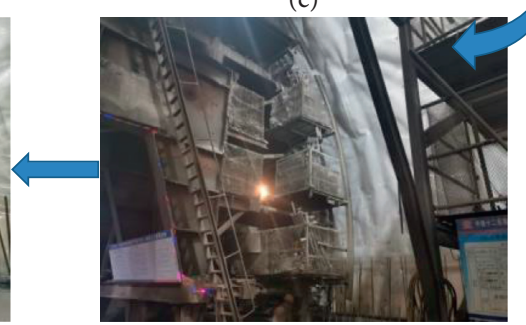

(d)

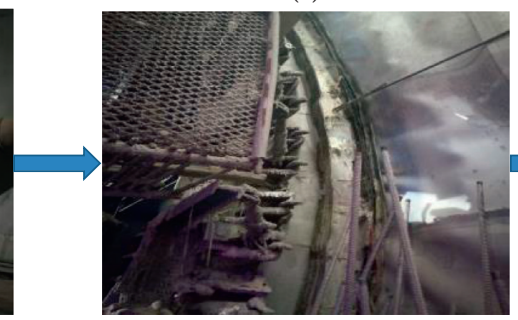

(h)

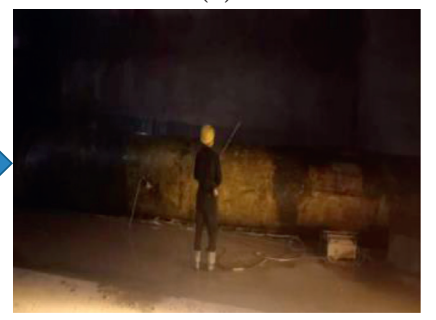

(i)

Figure 3: Process drawing of secondary lining: (a) tying of reinforcement, (b) clamping of secondary lining back arch, (c) pouring of secondary lining back arch, (d) pouring of road surface, (e) tying of ring reinforcement, (f) ring clamping, (g) pumping of concrete, (h) ring dismantling of mold, and (i) maintenance.

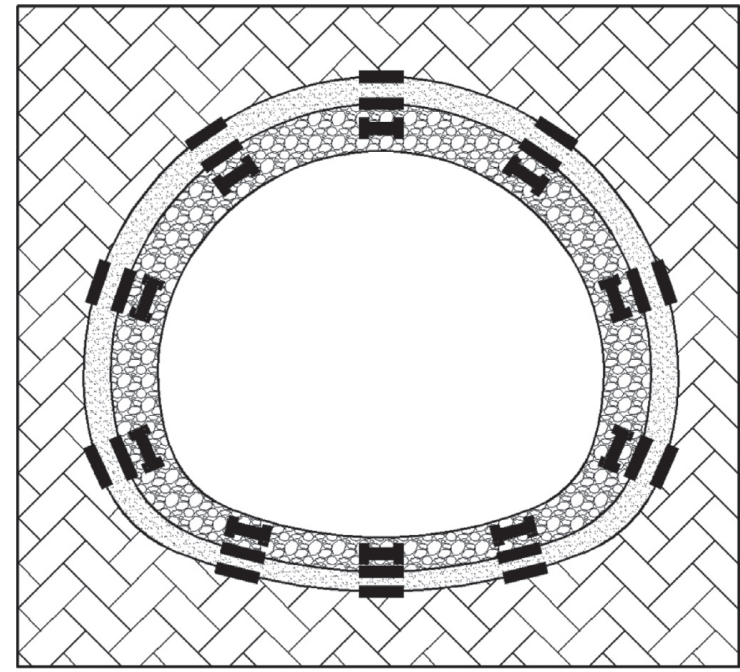

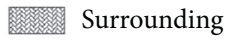

Initial support

Secondary lining

Earth pressure box

Concrete strain gauge

FIGURE 4: Schematic diagram of measuring point arrangement.

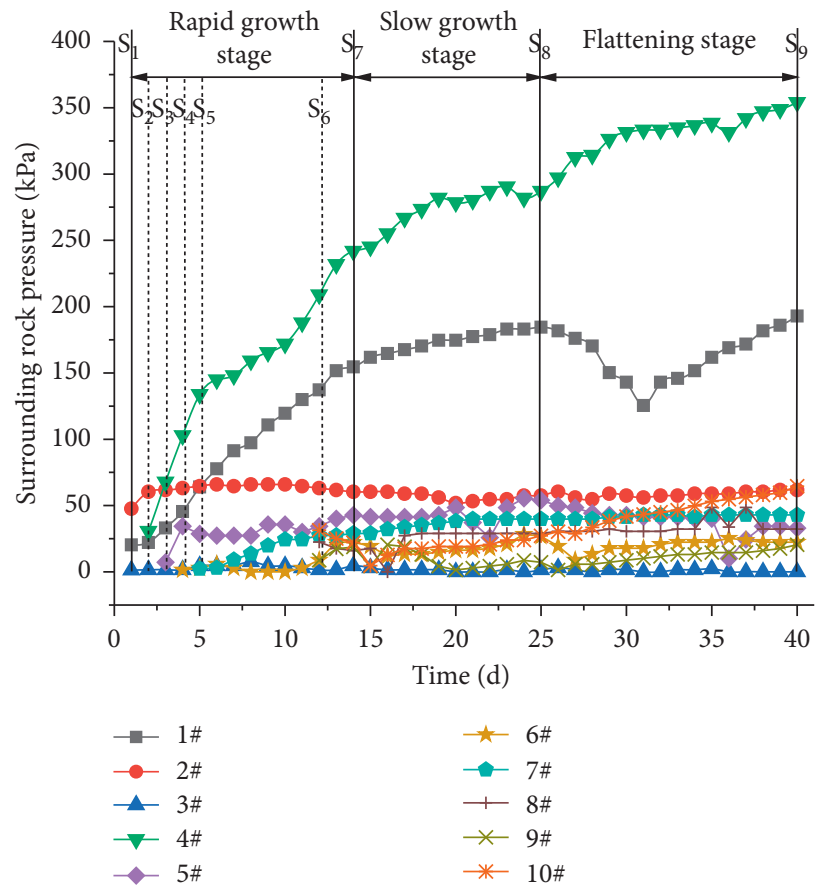

FIGURE 5: Pressure change curve of surrounding rock of DK$190+617$ miles in early three tunnels. 


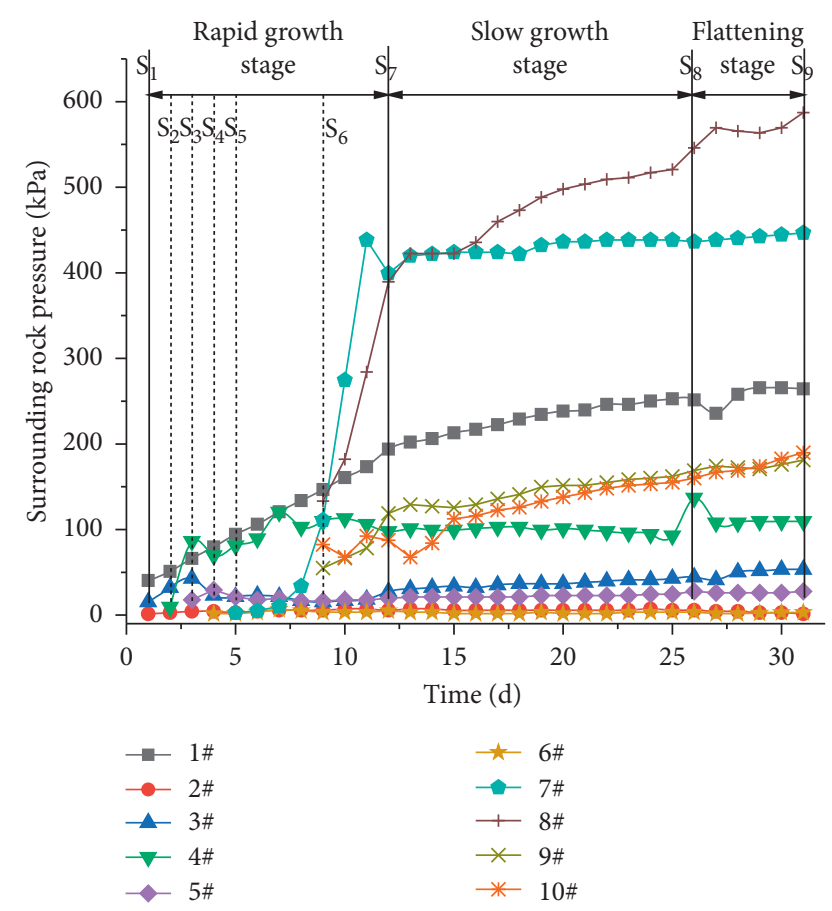

FIgURE 6: Pressure change curve of surrounding rock of DK$190+645$ miles in early three tunnels.

(1) From the variation curve of the surrounding rock pressure, the surrounding rock pressure changes to different degrees after the earth pressure box is installed at each measuring point of the above two sections, and the overall trend is increasing. This condition is caused by the gradual increase in the excavation area and the enlargement of the surface, thereby increasing the influence of unloading. However, the trends of the surrounding rock pressure increase rapidly at some measuring points and slowly at others due to the different locations and constraints of each measuring point.

(2) The change in stress can be divided into three stages, namely, rapid growth, slow growth, and flattening stages. This condition is based on the variation law of surrounding rock pressure with time and the time node of specific construction steps. The corresponding time nodes are "construction of secondary lining inverted arch" and "construction of circular secondary lining." The scope of the confining pressure loose circle gradually increases with the increase in the excavation section area when the initial support has not formed a ring. This condition occurs because the tunnel where the measuring point is located adopts the "three benches and seven steps" excavation method. The arch only relies on concrete and foot lock bolts to bear all the surrounding rock pressure, and the surrounding rock pressure shows rapid growth. The ringing of the initial support leads to a redistribution of pressure on the surrounding rocks. However, the initial support lacks the external stability constraint, thereby causing a rapid increase in pressure on the surrounding rock at some measurement points. Therefore, the period from "step up excavation" to "application of secondary lining backdrop" is defined as the "rapid growth phase." A thick layer of fill is poured immediately when the secondary lining backdrop is applied. This process is equivalent to providing hinge support restraint for the initial support of the elevated arch area and limits the initial deformation and growth of the surrounding rock pressure. The pressure on the surrounding rock shows a slow growth trend. The circumferential secondary liner consists of circumferential steel reinforcement and $50 \mathrm{~cm}$ thick C40 concrete. The thick high-strength concrete limits the initial deformation and restrains the growth of pressure in the surrounding rocks after the liner is applied. This stage is called the "levelling stage."

(3) The enclosure pressure variation curve shows that the enclosure pressure fluctuates at some points in time but does not affect the overall trend of the curve. During the installation of the soil pressure box, the pressure box must be closed to the surrounding rock, and the back end must be tightly fixed to the steel mesh. Although the surrounding rock is leveled, a gap is found between the pressure box and the surrounding rock due to the uneven surface of the surrounding rock or the welding process of the fixed end. The concrete fills the pores when high-pressure shotcrete is used, thereby causing the pressure box readings to jump.

(4) The contact pressure envelope diagram of the monitoring section is composed of the values after the perimeter pressure is stabilized (last day of monitoring), as shown in Figures 7 and 8. The marks of each measuring point in the drawing are expressed as fractions. The numerator position is the initial value of the surrounding rock pressure measured by the upper bench excavation, and the denominator is the value obtained when the measured data are stable. The numerator and denominator values correspond one-to-one to the envelope diagram. A small number of measurement points in the figure show $0 \mathrm{kPa}$ after the perirock pressure is stabilized. This condition is thought to be caused by the failure of the monitoring instrument at this point. From the spatial distribution, DK-190+617 has a high pressure on the top and left sides of the arch. In DK-190 + 645, the high values of perirock pressure are concentrated at the top of the vault, the left arch foot, and the right small sidewall. The maximum value of the surrounding rock pressure in the two sections is $587.2 \mathrm{kPa}$, and the pressure value of most measuring points is less than $120 \mathrm{kPa}$. Therefore, the pressure in the soil tunnel is slight, and the measured pressure distribution is contrary to the traditional symmetric load distribution in deep-buried tunnels.

(5) As an essential basis of tunnel structure design, the calculation of surrounding rock pressure ensures the 


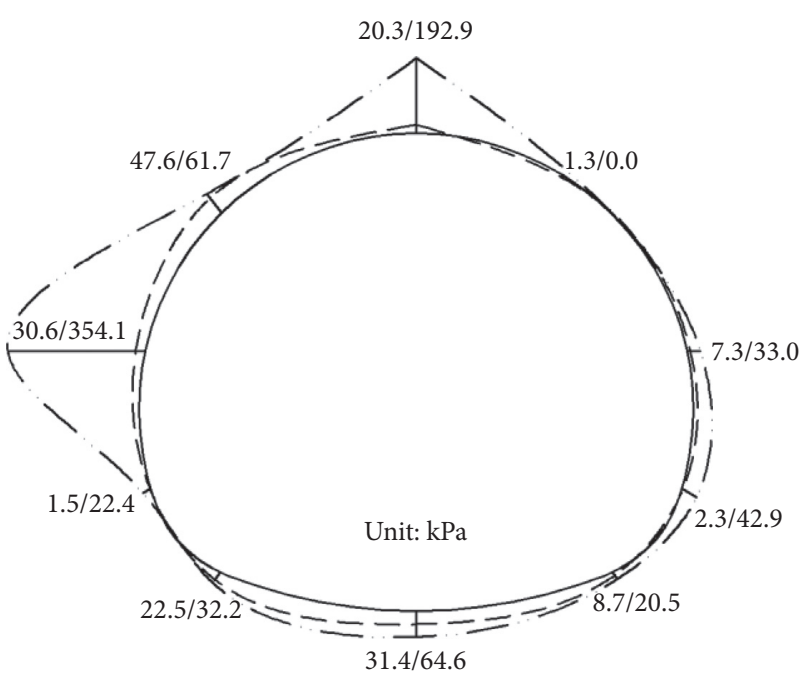

_ Tunnel contour
$\ldots$ - Initial envelope of contact pressure
$\ldots$ Envelope diagram of contact pressure stability

FIGURE 7: DK-190+617 mileage surrounding rock pressure envelope diagram of Zaosheng Tunnel.

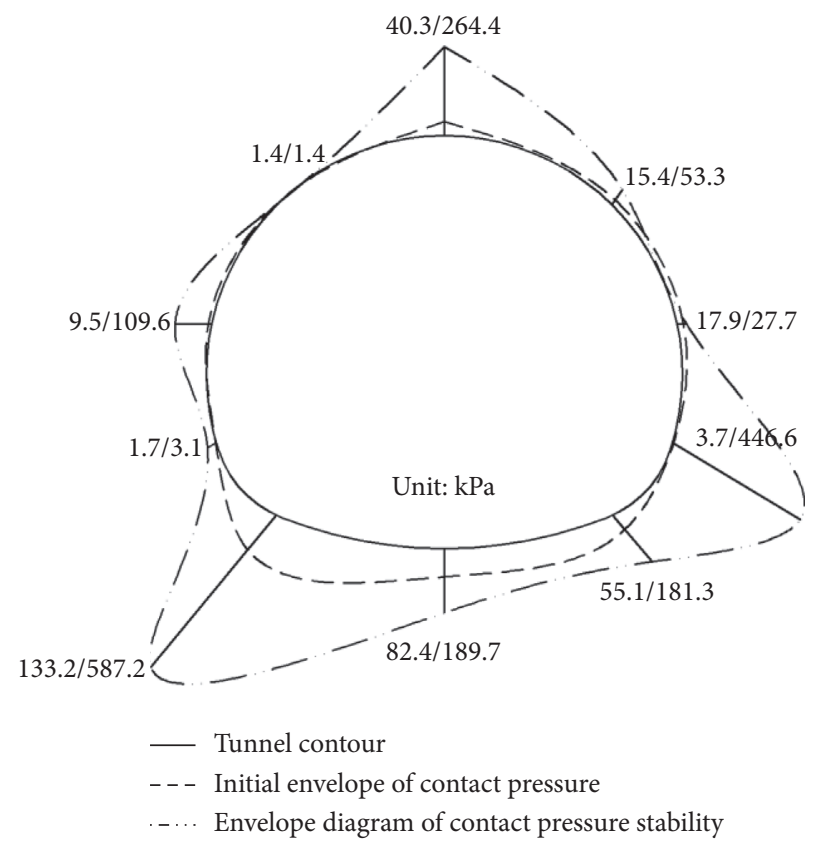

FIGURE 8: DK-190 + 645 mileage surrounding rock pressure envelope diagram of Zaosheng Tunnel.

safety of tunnel construction and operation. This study decomposes the measured radial pressure values in accordance with the horizontal and vertical directions. The measured results are compared with the measured average values, the railway tunnel design code, Platts theory, Terzaghi's theory, and the calculation values of the Caquot formula (Figures 9 and 10 for details). In terms of quantity, the longitudinal load under the same buried depth, same section, and exact calculation parameters is expressed as Platts theory $>$ Railway tunnel design code $>$ Terzaghi's theory $>$ Caquot formula. For the horizontal load, most of them show the function of buried depth, making the horizontal pressure distribution along the buried depth show unequal distribution law. The vertical pressure of the DK190+617 mileage is relatively gentle, and the maximum value is the arch crown between the two measured mileages. The measured values of other measuring points are slightly less than the theoretical calculation values of the tunnel gauge, except for the vault measuring points. For the DK190+617 mileage, the values of other measuring points are slightly smaller than the theoretical calculation value of tunnel gauge, except for some measuring points. The theory is reasonable in calculating the vertical surrounding rock pressure of the soil tunnel. However, it needs to be combined with a large number of measured results for the statistical analysis of a specific distribution form.

3.2. Contact Pressure. The contact pressure measured during monitoring is mainly the readings from the soil pressure box placed between the primary support and the secondary lining. In field monitoring, the secondary lining back arch is usually applied first for approximately 14 days ( 2 weeks) of step excavation under the same mile. However, some differences are found between different miles. The contact pressure beginning time point does not start from "1" because the contact pressure is consistent with the perimeter pressure described above for the construction steps at the same time and same mileage. Construction nodes " $\mathrm{S}_{7}$ " and " $\mathrm{S}_{8}$ " are marked in the figure to clarify the influence of construction steps on the variation pattern of contact pressure. The time refers to the completion of waterproofing plate laying and reinforcement tying work at this point. The pouring of the concrete occurs after the sensors are installed.

The contact pressure measured by the soil pressure box is not the "perirock pressure" due to the limitation of testing means. This pressure is completely transferred from the primary support to the secondary lining. The interaction between the primary support and secondary lining, that is, the "perirock resistance," is considered. However, the value obtained is the external load on the secondary lining when the contact pressure is stable. This value is important for analyzing the internal force distribution between the initial support and the secondary lining:

(1) The contact pressure of the monitoring section is plotted as shown in Figures 11 and 12. In accordance with the monitoring results, the amplitudes with the change in contact pressure of the tunnel back arch parts are small, and the curve change is stable. However, some individual points with sudden growth or a sharp increase are observed. In accordance with the tunnel back arch construction technology, the initial support well inhibits the 


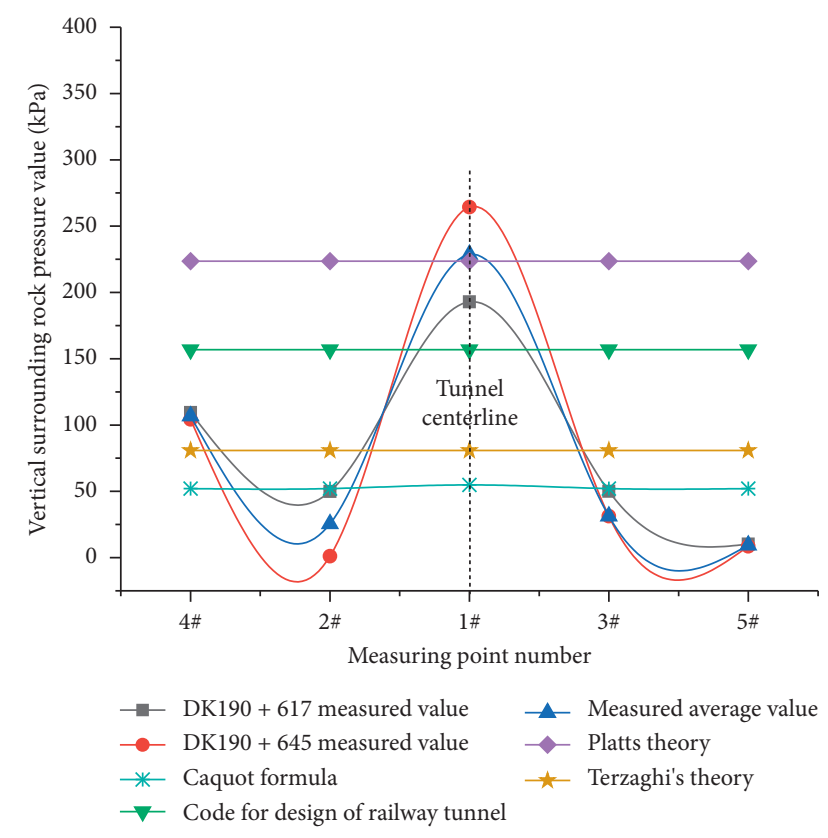

FIGURE 9: Pressure distribution of vertical surrounding rock at each measuring point.

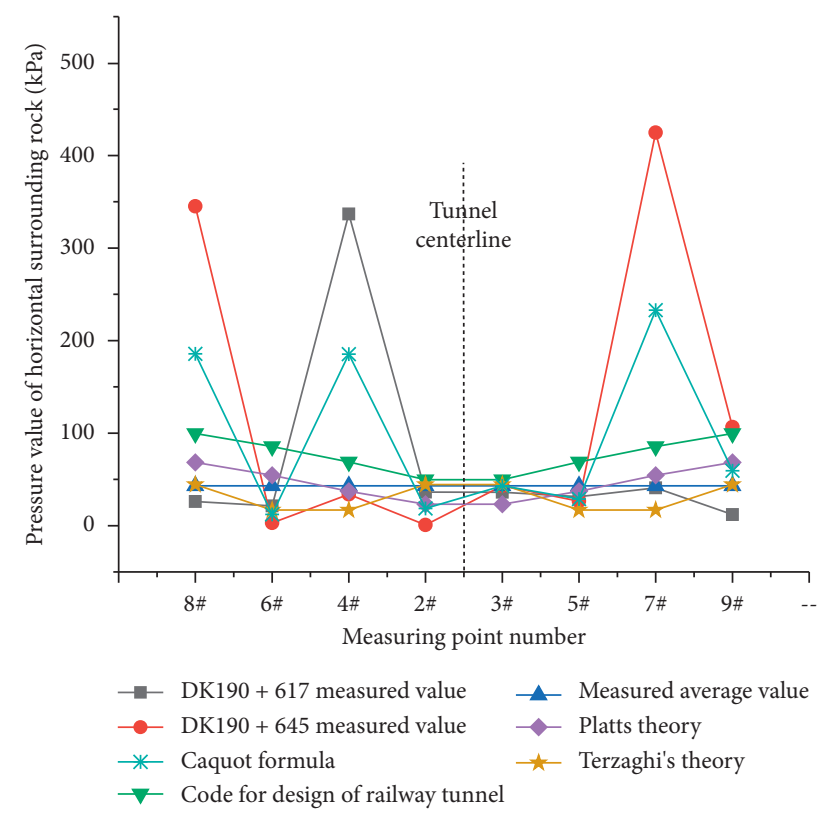

FIgURE 10: Pressure distribution of horizontal surrounding rock at each measuring point.

deformation of the surrounding rock when the initial support closed-loop is tied to the secondary lining reinforcement. The two lining back arches are applied when their strength reaches the basic standard and the filling structure is established. Mass concrete can restrain the deformation of the initial support, thereby providing the pressure box with some counterforce support. Some individual points with sudden growth or a sharp increase are due to the

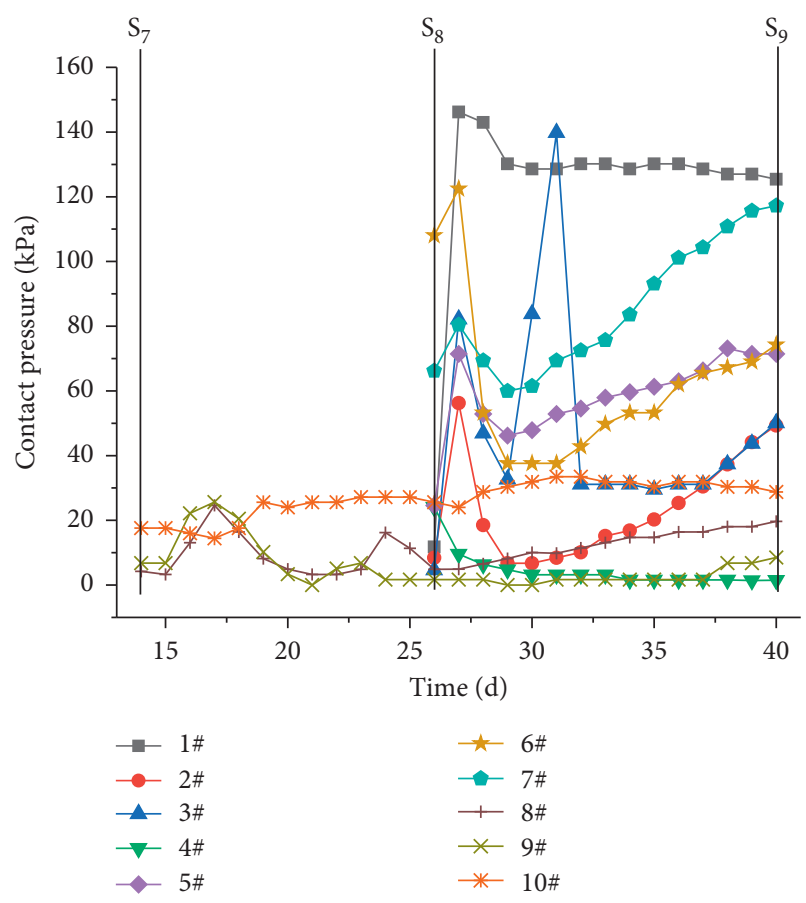

FIGURE 11: Change curve of DK-190 + 617 mileage contact pressure in early three tunnels.

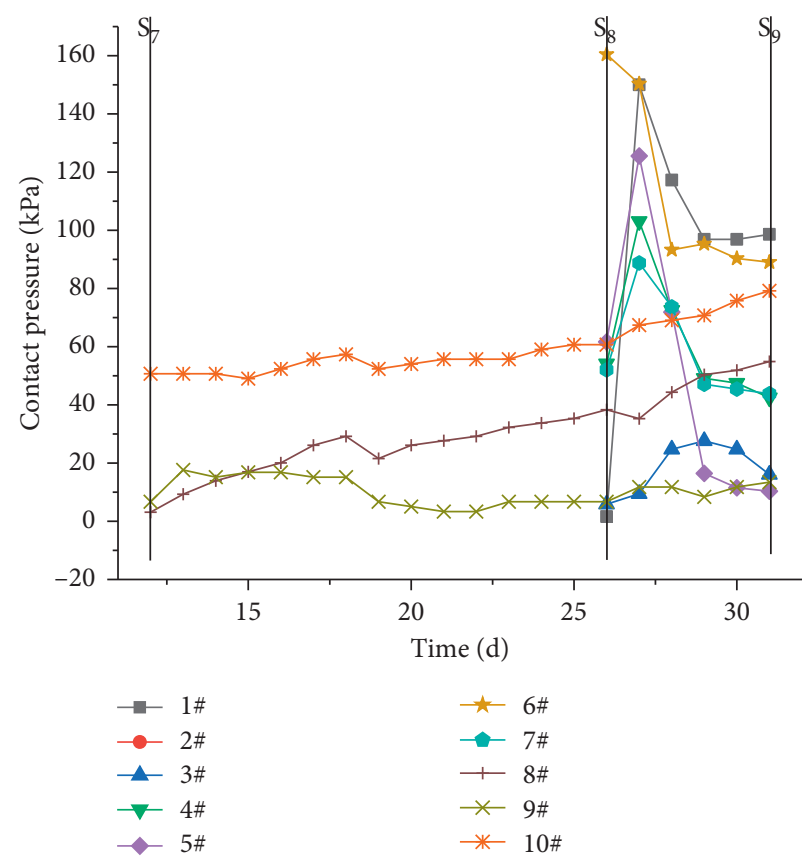

FIGURE 12: Change curve of DK-190 + 645 mileage contact pressure in early three tunnels.

installation of the pressure box, and a particular gap is found between the contact surfaces. Concrete pouring fills the gap. With the increase in concrete strength, the contact pressure between the two is constantly changing and specifically shows a trend of rapid growth. 
As shown in the curve of contact pressure changing with time, the secondary lining of the arch has a minimal effect on the contact pressure at the measuring point of the inverted arch. The strength of inverted concrete is formed at this time and is less affected by external factors because the construction time difference between the two is more than 10 days.

(2) The construction technology of secondary lining arches is complex, and circular formwork is mainly used to form concrete. Therefore, the integrity of the formwork and the strength of the Jack at each place have a great impact on the bearing capacity and surface smoothness of the concrete lining. In accordance with the curve of contact pressure changing with time, the pressure of the secondary lining arch can be divided into three stages: rapid increase, rapid rebound, and slow growth. The concrete is poured immediately after the arch sensor is installed. However, the demand is great, and the time is extended because pouring is often conducted with the adjacent four slab linings. The arch concrete is poured when monitoring and measuring the next day. At this time, the concrete is still in a semiflow state, the concrete strength is not formed, and the concrete self-weight acts on the pressure box, making its value increase significantly. The contact pressure between the primary support and the secondary lining has a sharp rebound stage when the arch is applied with the secondary lining for 2-3 days. This condition is an important stage of concrete stress redistribution and an important development of the concrete strength stage. With the increase in concrete strength, the interaction between the concrete and circumferential reinforcement makes them become a whole. This condition shares the contact pressure between the primary support and the secondary lining. Under the combined action of formwork construction technology and concrete self-weight, the contact pressure value and distribution law are greatly affected in this stage. The effect of the hydration heat of mass concrete on stress redistribution should not be underestimated. When the secondary lining is allowed to set for 4-5 days, the contact pressure tends to be stable, and the concrete strength basically does not change at this time. The formwork is then removed, and the lining enters the maintenance stage.

(3) It can be seen from the contact pressure envelope in Figures 13 and 14 of the test section that the overall value of the contact pressure is small, at less than $200 \mathrm{kPa}$, regardless of the initial or stabilized value.

(4) When the monitoring data tend to be stable, the contact pressure in the spatial distribution is top$>$ arch foot $>$ two waist distribution law, but the regularity of the back arch part is not apparent. This condition is because the two are conducted separately as independent steps with a time interval of

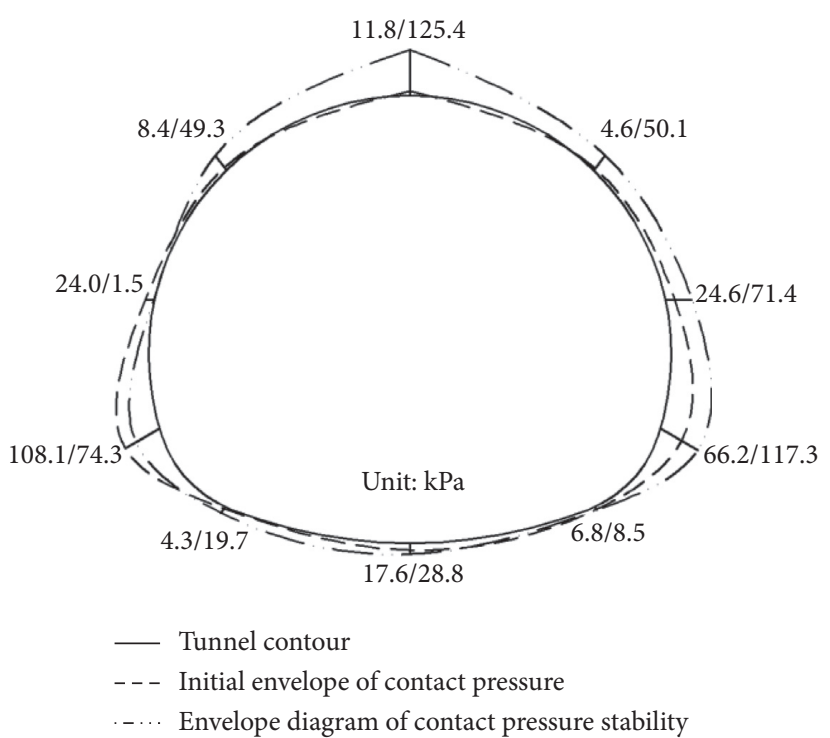

Figure 13: Envelope diagram of early third tunnel DK-190+617 mileage contact pressure.

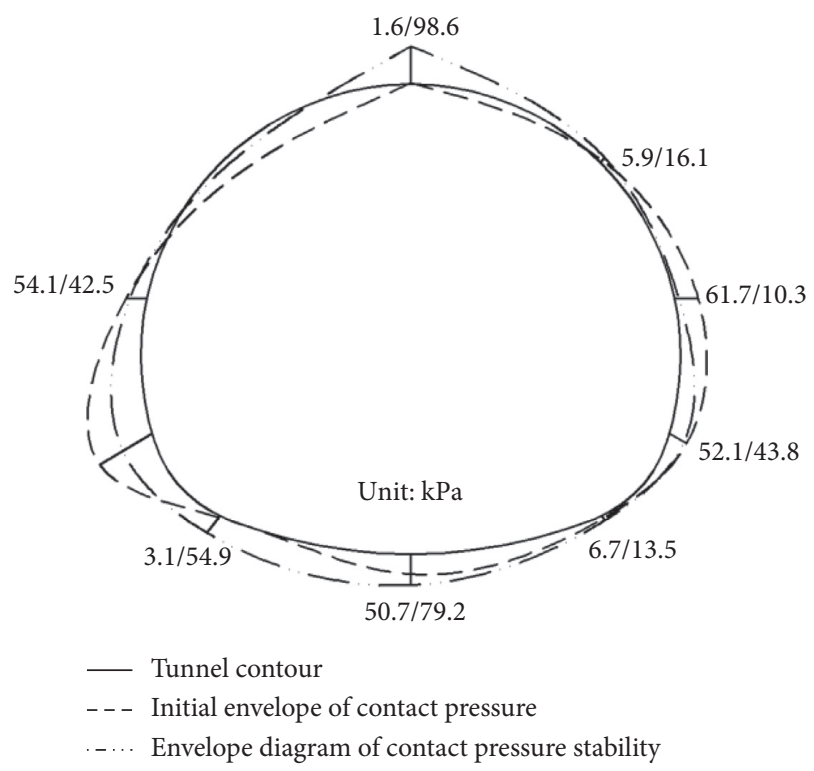

FIGURE 14: Envelope diagram of early third tunnel DK-190 + 645 mileage contact pressure.

more than 10 days during the construction of the secondary lining. The strength and stiffness are close to the design value when the concrete of the back arch is already formed, and the construction of the arch does not affect the stress distribution.

(5) The inverted arch part and arch part of the secondary lining can be analyzed as an independent construction sequence. However, the contact pressure of the two parts does not show a good symmetrical relationship on the two sides of the tunnel. This condition is similar to the spatial distribution of the surrounding rock pressure and is contrary to the symmetrical load form of a deep tunnel. 
(6) The surrounding rock pressure is compared with the contact pressure of the direct support and secondary lining, and the load sharing situation is calculated; see Table 2 for details. Some problems are found in the measuring equipment of the DK-190+617 mileage 3\# measuring point and the DK-190+617 mileage $2 \#$ measuring point. This condition makes the load sharing situation at this point impossible to calculate. Although the load sharing ratio can be calculated at the measuring point of DK-190+645 mileage $2 \#$ measuring point, the value is 28.7 . The result is seriously distorted, and the possibility of instrument damage is found. The positions of measuring points $4 \#$ and $5 \#$ for each section are adjusted to facilitate the load sharing of specific parts of the lining. Thus, the left and right sides of the arch waist position can be well distinguished.

From the monitoring results, the load sharing ratio of other measuring points ranges between 0.0 and 3.0, except for the damaged measuring points. The load sharing ratio is $0.0-0.7$, accounting for $76 \%$ of the total number of measuring points. The load sharing exhibits great differences due to some differences in the distribution of surrounding rock pressure, initial support, and secondary lining contact pressure between the two monitoring sections. The load sharing ratio of the DK-190+645 mileage is small and less than 0.4 . The monitoring results show that the load sharing ratio is relatively large at the arch waist and vault but relatively small at the inverted position.

\subsection{Internal Force of Secondary Lining Concrete. During the} on-site monitoring, the secondary lining concrete of the tunnel is monitored with a concrete strain gauge. The monitoring results show that the measured points are microstrain values. The strain is converted into internal concrete pressure through calculation to facilitate the reader's understanding. The following curve of the internal force of the secondary lining concrete with time is plotted; see Figures 15 and 16 for details.

(1) The internal concrete force, as an important index of the strength of the secondary lining, plays a decisive role in the bearing capacity of the lining. In accordance with the field monitoring results, most of the measurement points of the secondary lining are under good pressure, with the maximum concrete stress of $17 \mathrm{MPa}$, which is less than the ultimate compressive strength of concrete. Some back arch measurement points show tensile conditions.

(2) Most of the measurement points of the internal concrete forces of the secondary lining undergo a sharp increase and a slow return in the range of 1 to 4 days of concrete placement. The maximum internal concrete force occurs at one day of concrete order, which is an important time for the initial damage of the lining to develop. The internal pressure of concrete is adjusted at approximately 2 to 4 days. Concrete pouring for 1 to 4 days is usually the main stage of concrete strength formation. Under the joint restraint of the initial support and formwork, the internal concrete force is adjusted to a certain extent. The internal pressure of the concrete shows an increasing trend after stabilization.

(3) Comparing the change curve of the internal concrete force with the change curve of the contact pressure of the surrounding rock, the correlation between the two is low at the back arch site. This finding is because the back arch site has a thick concrete layer, and the contact pressure has minimal influence on it. However, this condition is not the case for the arch. One day after the secondary lining of the arch, the contact pressure and internal concrete force are mutated with time. From the time point of view, the concrete filled the gap between the pressure box and the initial support and wrapped the concrete strain gauge after pouring, thereby sharply increasing the sensor readings. The contact pressure was adjusted back to a specific range, and the internal concrete force remained stable. With the change in concrete strength, the contact pressure between the initial support and the second liner was adjusted to a certain extent. Therefore, the resistance of the surrounding rock between the two is continuously adjusted with the changes in concrete strength.

(4) It can be seen from the concrete envelope in Figures 17 and 18 of the test section that the maximum compressive stress values of the two fracture surfaces appear in the left small sidewall (measuring point (6)) and the right-side arch (measuring point (2)) after the measured data are stable. The measured values are 12.3 and 15.9, which are less than the ultimate compressive strength of concrete. By contrast, the tensile stress is concentrated in the inverted arch, which is located at the right arch foot and arch bottom, where the tensile stress is greater than the ultimate tensile strength.

(5) The concrete and contact pressure have no common characteristics in terms of quantity and distribution by comparing their envelope diagrams. For the DK$190+617$ mileage, the contact pressure at the right arch waist position is significantly greater than that at the left arch waist position. However, in the concrete internal force envelope diagram, the concrete internal force values of the two measuring points are opposite. Therefore, the internal force of the tunnel lining is less affected by contact pressure and may be affected by hydration heat or formwork construction.

(6) The internal force distribution of DK-190+645 mileage concrete is relatively symmetrical, but the regularity of DK-190+645 mileage is insufficient. Therefore, some problems with symmetrical loads are found in the deep tunnel lining designs. A large number of field measurements should be conducted to clarify the internal force mechanism of secondary lining concrete. 
TABLE 2: Load sharing of primary support and secondary lining.

\begin{tabular}{|c|c|c|c|c|c|c|c|c|c|c|c|}
\hline Measuring point & Position & Mileage & $P_{1}$ & $P_{2}$ & $\left(P_{2} / P_{1}\right)$ & $\overline{\left(P_{2} / P_{1}\right)}$ & Mileage & $P_{1}$ & $P_{2}$ & $\left(P_{2} / P_{1}\right)$ & $\overline{\left(P_{2} / P_{1}\right)}$ \\
\hline $1 \#$ & & \multirow{10}{*}{ DK-190+617 } & 192.9 & 125.4 & 0.65 & \multirow{6}{*}{1.67} & \multirow{10}{*}{ DK-190+645 } & 264.4 & 98.6 & 0.37 & \multirow{3}{*}{0.34} \\
\hline $2 \#$ & Vault & & 61.7 & 49.3 & 0.80 & & & 1.4 & (Poor) & (Poor) & \\
\hline $3 \#$ & & & 0 & 50.1 & (Poor) & & & 53.3 & 16.1 & 0.30 & \\
\hline $4 \#$ & Left & & 354.1 & 1.5 & 0.01 & & & 109.6 & 42.5 & 0.39 & \multirow{3}{*}{0.39} \\
\hline $6 \#$ & Arch & & 22.4 & 74.3 & 3.32 & & & 3.1 & 89.0 & 28.7 (poor) & \\
\hline $5 \#$ & Right & & 33.0 & 71.4 & 2.16 & & & 27.7 & 10.3 & 0.37 & \\
\hline 7\# & Spandrel & & 42.9 & 117.3 & 2.73 & \multirow[t]{2}{*}{2.45} & & 446.6 & 43.8 & 0.10 & \multirow[t]{2}{*}{0.24} \\
\hline $8 \#$ & & & 32.2 & 19.7 & 0.61 & & & 587.2 & 54.9 & 0.09 & \\
\hline 9\# & Inverted & & 20.5 & 8.5 & 0.41 & \multirow{2}{*}{0.49} & & 181.3 & 13.5 & 0.07 & \multirow{2}{*}{0.09} \\
\hline $10 \#$ & & & 64.6 & 28.8 & 0.45 & & & 189.7 & 19.2 & 0.10 & \\
\hline
\end{tabular}

$P_{1}$ refers to the pressure between the surrounding rock and initial support, unit $k P a ; P_{2}$ refers to the pressure between the surrounding rock and initial support, unit $\mathrm{kPa} ;\left(P_{2} / P_{1}\right)$ refers to the load sharing ratio, unit: $0.01 ; \overline{\left(P_{2} / P_{1}\right)}$ refers to the average load sharing ratio, unit: 0.01 .

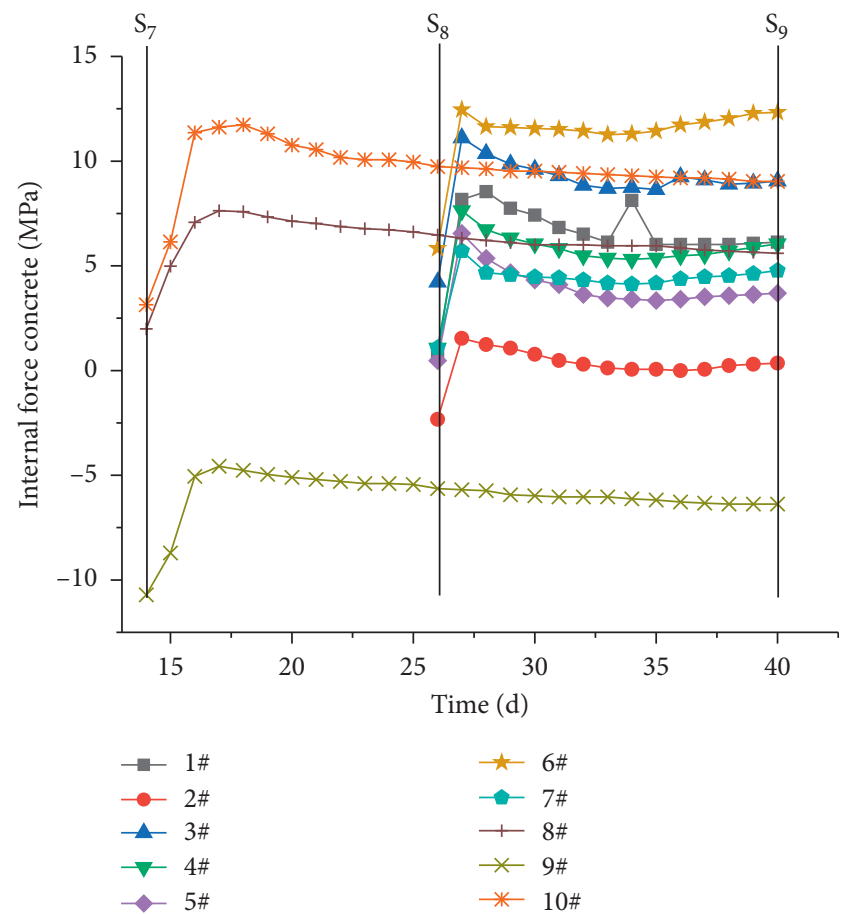

FIGURE 15: DK-190 + 617 mileage concrete internal force change curve of Zaosheng Tunnel.

\section{Stress Release Rate during Tunnel Excavation}

During the tunnel excavation process, the temporal and spatial effects of the surrounding rock pressure are obvious. Three conditions of the spatial relationship between the target and excavation sections are found after the target end face is selected. These conditions are as follows: the target section is after the excavation section, the target section coincides with the excavation section, and the target end face is before the excavation section. All three conditions have some influence on the pressure at the target end face. However, the traditional field test method can only reflect the working condition of the target section before the excavation section. The concept of the stress relief rate is introduced to describe the stress changes in the surrounding rocks during the entire tunneling process and to directly

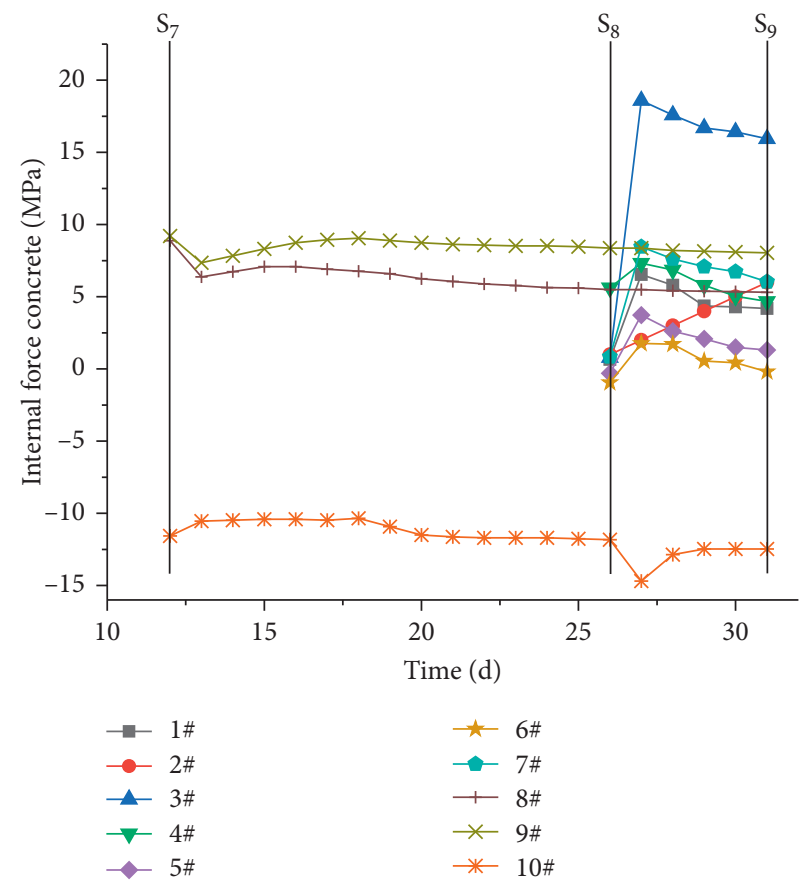

FIGURE 16: DK-190 + 645 mileage concrete internal force change curve of Zaosheng Tunnel.

reflect the impact of the target section during the whole tunneling process [24].

Initial stress fields, including self-weight and structural stress fields, are found in the stratum. Tunnel excavation is a process of stress release. Tunnel excavation inevitably causes the changes in the initial stress field of the soil around the excavation area because it is closely related to the release of internal constraints. Part of the initial stress is transformed into the pressure acting on the tunnel support, and the other part is borne by the surrounding rock of the tunnel itself. As an essential manifestation of stress release, the displacement change is considered to be approximately equivalent to the stress release rate [25]. Therefore, the displacement release rate is used rather than the stress release rate to solve the relationship between the displacement release rate, excavation, and target section distance. 


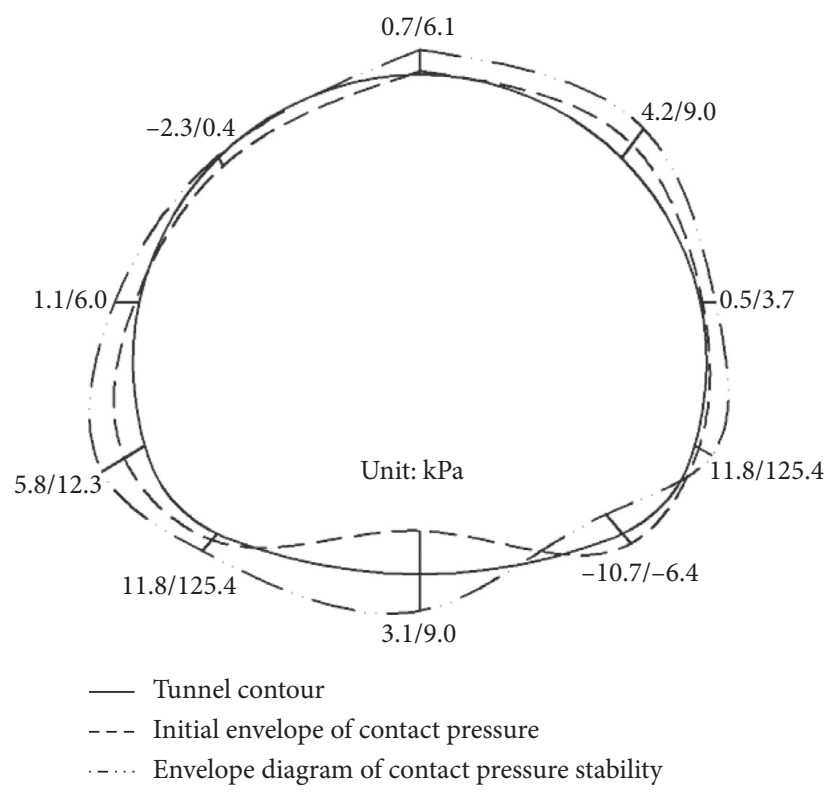

FIGURE 17: DK-190 + 617 mileage concrete internal force envelope diagram of Zaosheng Tunnel.

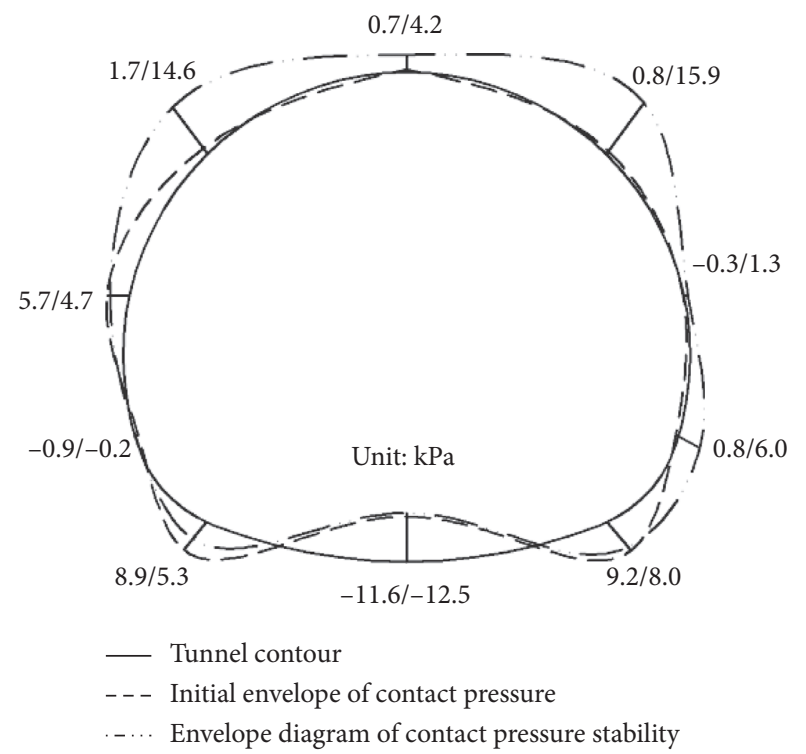

FIGURE 18: DK-190 + 645 mileage concrete internal force envelope diagram of Zaosheng Tunnel.

In this study, the finite element software MIDAS is used to establish a tunnel model with $60 \mathrm{~m}$ footage (50 cycles) based on the measured tunnel. The constraints are set at the left and right, front, and rear of the model, and the equivalent load is applied on the upper part. The Mohr-Coulomb criterion is adopted for the surrounding rock. The test points at $18 \mathrm{~m}$ (15th cycle) are selected as the target cross section (see Figure 19 for details). Five test points are set at the vault, left, and right spandrels, and these points are numbered as 1, 2, 3, 4, and 5, respectively. The positions of each measuring point are the same as the measured positions. In the test process, taking the tunnel footage direction as the independent variable, the single excavation footage is consistent with the actual situation, and the target end face is defined as $x=0, x<0$ when the tunnel is not excavated, and $x \geq 0$ when the tunnel is excavated. The secondary lining effect is not considered in this model, and only the excavation and initial support process are simulated due to the complexity of the composite lining structure.

In the numerical calculation, the position of the measuring point is marked, the vertical displacement of the monitoring point after each excavation is counted, and the deformation curve of the surrounding rock is drawn as follows. The surrounding rock begins to deform before the excavation face passes through the monitoring section, but the deformation is relatively small. With the progress of the excavation surface, the deformation of the monitoring point gradually develops. Specifically, the displacement of the measuring point changes suddenly when the excavation face is close to the monitoring section. The displacement of the measuring point increases gradually and tends to be stable when the excavation face is gradually far away from the monitoring section. The surrounding rock deformation tends to be stable when the excavation section is 19 cycles away from the monitoring section (3 times the tunnel diameter). Similarly, the deformation of measuring point $1 \#$ in the tunnel is the largest, which is approximately $14.42 \mathrm{~mm}$, when the tunnel deformation tends to be stable. The longitudinal deformation of the two waist measuring points is the smallest, which is 6.84 and $6.68 \mathrm{~mm}$, respectively, as shown in Figure 20.

The displacement release rate of the surrounding rock is analyzed by selecting measuring point $1 \#$ with a large displacement. The functional relationship between the displacement release rate and distance between the excavation face and monitoring point is fitted. Zhang [26] compared the functional relation of the displacement release rate of Lee, Panet, Zhao and considered that the modified formula derived has strong applicability [27]. The specific equation is expressed as follows: 


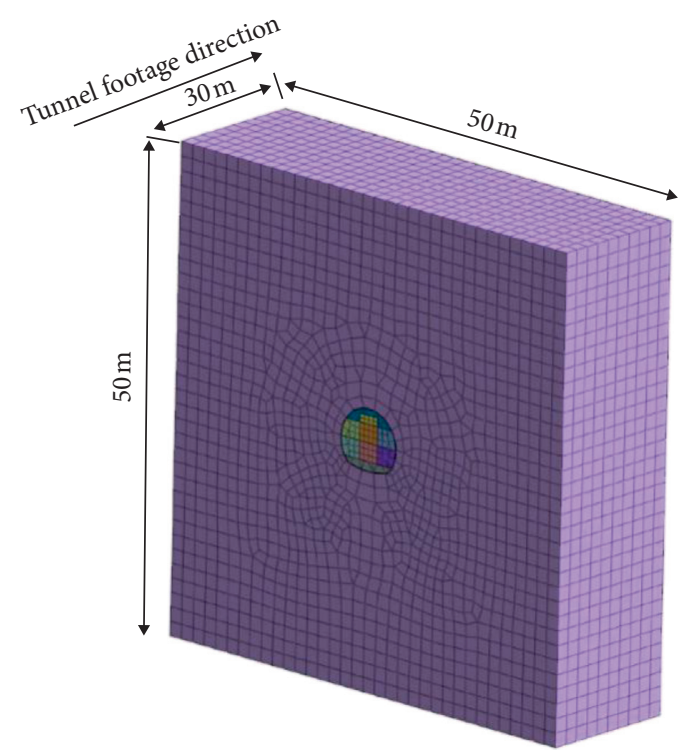

Figure 19: Schematic diagram of the tunnel model.

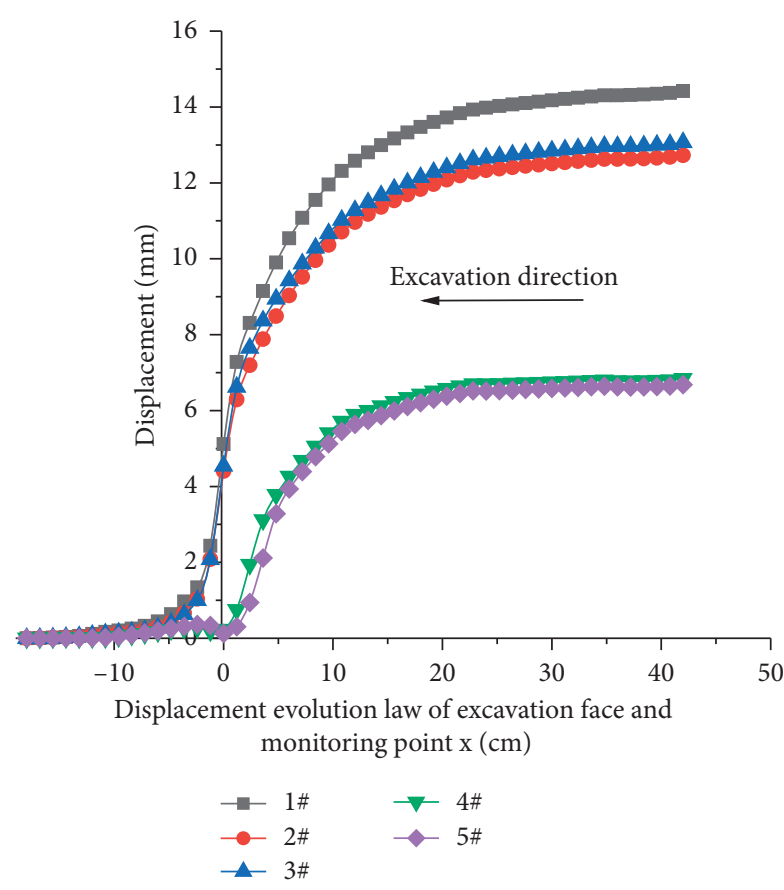

FIgURE 20: Deformation law of tunnel measuring points.

$$
\lambda= \begin{cases}\left(1-\lambda_{0}\right)\left(1-e^{\frac{x}{X}}\right)+\lambda_{0}, & (x \geq 0), \\ \lambda_{0} e^{\frac{x}{X_{1}}} & (x<0),\end{cases}
$$

where $x$ is the distance between the excavation fault surface and the monitoring section, $\mathrm{m} ; \lambda_{0}$ is the displacement release coefficient when the excavation section is the monitoring section, that is, the ordinate of the intersection point with the longitudinal axis; $X$ is a constant; and $X_{1}=\lambda_{0} / 1-\lambda_{0} X$ is a constant.

In the fitting process, the fitting degree between the calculated results and the test results is high when $x \geq 0$. However, the difference between the two is large when $x<0$, and the function relation does not conform to the tunnel involved in the project. Therefore, the exponent and constants $A, B, C$ are introduced to modify the parameters when the excavation surface does not reach the monitoring section $(x<0)$. The function relation is modified as

$$
\lambda=A \lambda_{0} e^{\frac{x}{B X_{1}}}+C, \quad(x<0) .
$$

We obtain the following function relationship through many sets of data inversions. The correlation coefficients in the piecewise function are $R_{1}{ }^{2}=0.9965$ and $R_{2}^{2}=0.9996$, and the fitting results are good. This formula can well reflect the relationship between the distance of the excavation tunnel and monitoring sections and the displacement release coefficient, which is expressed as

$$
\lambda=\left\{\begin{array}{cc}
0.6026\left(1-e^{\frac{x}{7.3186}}\right)+0.3974, & (x \geq 0), \\
0.2544 e^{\frac{x}{2.5756}}+0.0038, & (x<0) .
\end{array}\right.
$$

The stress release rate of the tunnel measuring point is compared with the displacement release result of the fitting function, and the curve is drawn, as shown in Figure 21. The fitting degree is high, and the effect is good. 


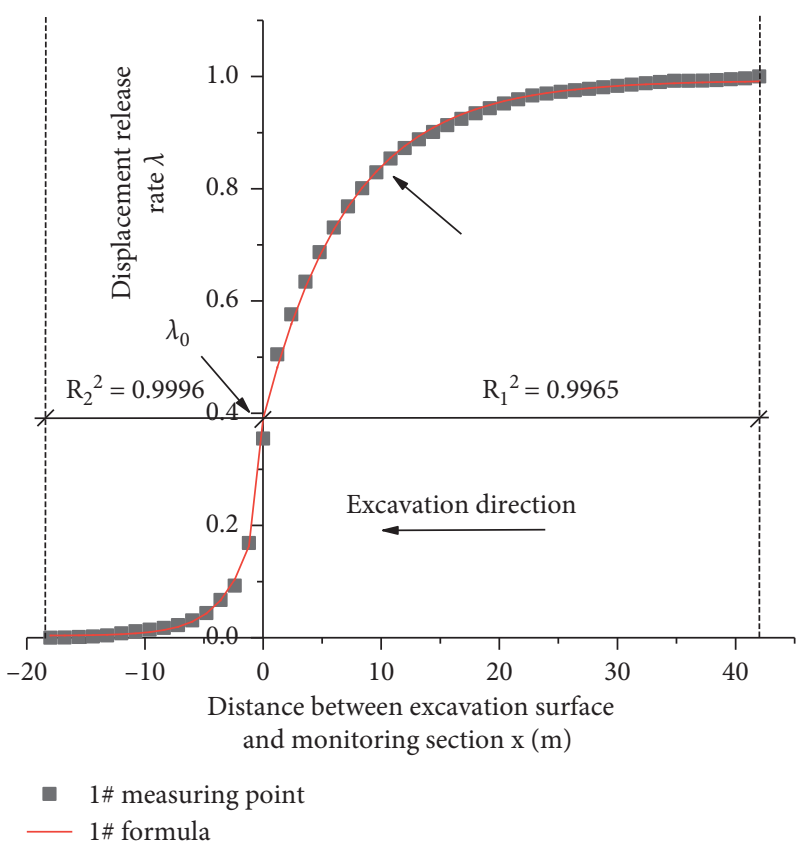

FIgURE 21: 1\# comparison chart of measuring points and fitting function results.

\section{Conclusion}

The conclusions based on the long-term monitoring and numerical calculation of the surrounding rock pressure, the pressure between the primary support and the secondary lining, and the secondary lining concrete of the Zaosheng No.3 tunnel on the Yinchuan-Xi'an railway are obtained as follows:

(1) In a large section tunnel with step construction, the pressure of the surrounding rock is greatly much disturbed by the construction. The stress state of the rock surrounding the tunnel is continuously adjusted as the lining is used one by one. The pressures in the tunnel perimeter are adjusted as the lining is applied one by one. The stresses in the tunnel edge are usually defined as "lined back arch" and "lined circumferential," with rapid, slow, and flattening increases. The maximum value of the monitored tunnel surrounding rock pressure is $587.2 \mathrm{kPa}$ (approximately $26 \mathrm{~m}$ loess column weight), and the vast majority of the surrounding rock pressures are less than $120 \mathrm{kPa}$ (approximately $5.5 \mathrm{~m}$ loess column mass). The tunnel gauge is reasonable for calculating the sheer perimeter pressure by breaking down the measured values in the horizontal and vertical directions. However, the horizontal pressure is complex, and the distribution is not a traditional symmetrical distribution.

(2) The results show that the amplitude of the contact pressure at the measuring points of the inverted tunnel with time is small. The curve changes smoothly, and the secondary lining of the arch has minimal effect on the contact pressure of the measuring point of the inverted arch. The change in the secondary lining arch pressure with time shows three stages: rapid growth, rapid rebound, and slow growth. The contact pressure tends to be stable after 4-5 days of secondary lining construction.

(3) Except for a few inverted arch measuring points showing tension, most of the measuring points the of large section soil tunnel show a compression state, and the value is less than the ultimate compressive strength. The results show that the concrete stress at the tension measuring point of the inverted arch is greater than the ultimate tensile strength. The internal force of the concrete reaches the maximum value in one day. The internal pressure of concrete is adjusted after 2-4 days of secondary lining, and the inner pressure of concrete remains stable.

(4) The overall value of contact pressure is small when the monitoring data of each measuring point tend to be stable. The test points $(76 \%)$ have pressure sharing ratio between 0 and 0.7 . The bearing capacity of the primary support accounts for the majority of the composite lining, and the stress of the secondary lining is relatively small.

(5) During the tunnel excavation process, the deformation (deformation release rate) of the surrounding rock gradually increases with the passage of the excavation section, and the deformation (deformation release rate) is the most severe when the excavation face is close to the monitoring section. With the increase in the distance between the excavation and monitoring sections, the deformation (deformation release rate) tends to be gentle.

The displacement release rate and the distance between the excavation and monitoring sections by fitting the piecewise function conform to the following functions:

$$
\lambda= \begin{cases}0.6026\left(1-e^{\frac{x}{7.3186}}\right)+0.3974, & (x \geq 0), \\ 0.2544 e^{\frac{x}{2.5756}}+0.0038, & (x<0) .\end{cases}
$$

\section{Data Availability}

The data used to support the findings of this study are included within the article.

\section{Conflicts of Interest}

The authors declare that they have no conflicts of interest.

\section{Acknowledgments}

The authors thank the workers, foremen, and safety coordinators of the main contractors for their participation. This work was supported by the National Natural Science Foundation of China (grant no. 42072319). 


\section{References}

[1] C. Zhang and K. Zeng, "Comparisons and applications of displacement release coefficients for a circular rock roadway subjected to isotropic geostresses," Chinese Journal of Rock Mechanics and Engineering, vol. 34, no. 3, pp. 498-510, 2015.

[2] Y.-N. Wei, W. Fan, B. Yu, L.-S. Deng, and T. Wei, "Characterization and evolution of three-dimensional microstructure of Malan loess," Catena, vol. 192, Article ID 104585, 2020.

[3] L. Zuo, L. Xu, B. A. Baudet, C. Gao, and C. Huang, "The structure degradation of a silty loess induced by long-term water seepage," Engineering Geology, vol. 272, Article ID 105634, 2020.

[4] H. Sadeghi, M. Kiani, M. Sadeghi, and F. Jafarzadeh, "Geotechnical characterization and collapsibility of a natural dispersive loess," Engineering Geology, vol. 250, pp. 89-100, 2019.

[5] L. Feng, H. Lin, M. Zhang, L. Guo, Z. Jin, and X. Liu, "Development and evolution of Loess vertical joints on the Chinese Loess Plateau at different spatiotemporal scales," Engineering Geology, vol. 265, Article ID 105372, 2020.

[6] E. Bakhtavar and Y. Shirvand, "Designing a fuzzy cognitive map to evaluate drilling and blasting problems of the tunneling projects in Iran," Engineering with Computers, vol. 35, no. 1, pp. 35-45, 2019.

[7] B. Tashayo, K. Behzadafshar, M. Soltani Tehrani, H. Afkhami Banayem, M. H. Hashemi, and S. S. Taghavi Nezhad, "Feasibility of imperialist competitive algorithm to predict the surface settlement induced by tunneling," Engineering with Computers, vol. 35, no. 3, pp. 917-923, 2019.

[8] X. Liu, G. Han, E. Wang, S. Wang, and K. Nawnit, "Multiscale hierarchical analysis of rock mass and prediction of its mechanical and hydraulic properties," Journal of Rock Mechanics and Geotechnical Engineering, vol. 10, no. 4, pp. 694-702, 2018.

[9] M. Hajihassani, R. Kalatehjari, A. Marto, H. Mohamad, and M. Khosrotash, "3D prediction of tunneling-induced ground movements based on a hybrid ANN and empirical methods," Engineering with Computers, vol. 36, no. 1, pp. 251-269, 2020.

[10] A. Mottahedi, F. Sereshki, and M. Ataei, "Development of overbreak prediction models in drill and blast tunneling using soft computing methods," Engineering with Computers, vol. 34, no. 1, pp. 45-58, 2018.

[11] Y. Luo, J. Chen, Z. Shi, J. Li, and W. Liu, "Mechanical characteristics of primary support of large span loess highway tunnel: a case study in Shaanxi Province, Loess Plateau, NW China primary," Tunnelling and Underground Space Technology, vol. 104, Article ID 103532, 2020.

[12] M. Du, X. Wang, Y. Zhang, L. Li, and P. Zhang, "In-situ monitoring and analysis of tunnel floor heave process," Engineering Failure Analysis, vol. 109, Article ID 104323, 2020.

[13] Y. Zhao, H. He, and P. Li, "Key techniques for the construction of high-speed railway large-section loess tunnels," Engineering, vol. 4, no. 2, pp. 254-259, 2018.

[14] K. Yertutanol, H. Akgün, and E. Sopac1, "Displacement monitoring, displacement verification and stability assessment of the critical sections of the Konak tunnel, İzmir, Turkey," Tunnelling and Underground Space Technology, vol. 101, Article ID 103357, 2020.

[15] Q.-Y. Zhang, M.-Y. Ren, K. Duan et al., "Geo-mechanical model test on the collaborative bearing effect of rock-support system for deep tunnel in complicated rock strata," Tunnelling and Underground Space Technology, vol. 91, Article ID 103001, 2019.
[16] T. Liu, Y. Xie, Z. Feng, Y. Luo, K. Wang, and W. Xu, "Better understanding the failure modes of tunnels excavated in the boulder-cobble mixed strata by distinct element method," Engineering Failure Analysis, vol. 116, Article ID 104712, 2020.

[17] X. Liu, F. Wang, J. Huang, S. Wang, Z. Zhang, and K. Nawnit, "Grout diffusion in silty fine sand stratum with high groundwater level for tunnel construction," Tunnelling and Underground Space Technology, vol. 93, Article ID 103051, 2019.

[18] B. Hu, H. Zhao, and S. Wang, "Pull-out model test for tunnel anchorage and numerical analysis," Rock and Soil Mechanics, vol. 30, no. 6, pp. 1575-1582, 2009.

[19] G. Xu, C. He, Q. Yang, and B. Wang, "Progressive failure process of secondary lining of a tunnel under creep effect of surrounding rock," Tunnelling and Underground Space Technology, vol. 90, pp. 76-98, 2019.

[20] S. Wang, L. Ruan, X. Shen, and W. Dong, "Investigation of the mechanical properties of double lining structure of shield tunnel with different joint surface," Tunnelling and Underground Space Technology, vol. 90, pp. 404-419, 2019.

[21] J. Su and A. Bloodworth, "Numerical calibration of mechanical behaviour of composite shell tunnel linings," Tunnelling and Underground Space Technology, vol. 76, pp. 107-120, 2018.

[22] M. Lei, L. Peng, and C. Shi, "Model test to investigate the failure mechanisms and lining stress characteristics of shallow buried tunnels under unsymmetrical loading," Tunnelling and Underground Space Technology, vol. 46, pp. 64-75, 2015.

[23] G. Xu, C. He, D. Lu, and S. Wang, "The influence of longitudinal crack on mechanical behavior of shield tunnel lining in soft-hard composite strata," Thin-Walled Structures, vol. 144, Article ID 106282, 2019.

[24] Y. Yang, J. Zheng, H. Lai, and X. Wu, "A revise method for calculating stress release ratio in tunnel excavation," Chinese Journal of Rock Mechanics and Engineering, vol. 34, pp. 2251-2257, 2015.

[25] G. Rui, F. Yong, and H. Chuan, "Study on the correlation between stress release and displacement release during tunnel excavation," Journal of Railway Engineering Society, vol. 9, pp. 46-49, 2010.

[26] Y. Zhang, K. Su, L. Zhou, and H. Wu, "Estimation of ground support installation time based on the tunnel longitudinal displacement of convergence-confinement method," Rock and Soil Mechanics, vol. 38, pp. 471-478, 2017.

[27] D. Zhao, L. Jia, M. Wang, and F. Wang, "Displacement prediction of tunnels based on a generalised Kelvin constitutive model and its application in a subsea tunnel," Tunnelling and Underground Space Technology, vol. 54, pp. 29-36, 2016. 